\title{
Artificial neural network modelling for asphalt concrete samples with boron waste modification
}

\author{
Mustafa Keskin* and Murat Karacasu \\ Department of Civil Engineering, Specialty of Pavement Engineering, Eskisehir Technical University, Eskisehir, Turkey \\ * Corresponding Author: mustafakeski@eskisehir.edu.tr
}

Submitted : 10/04/2019

Revised : 24/07/2021

Accepted :09/08/2021

\begin{abstract}
Civil engineering science has evolved into the 21 st century with concepts of recycling and sustainability. Create sustainable habitats by evaluating waste materials in building materials is one of the most important goals of this century. This study aims to eliminate the boron waste dunes that have occurred and continue to occur in Turkey, which has the world's largest boron reserves by using in road materials. Solid boron wastes obtained from the field were crushed and added to asphalt samples in certain ratios, and the effect of Crushed Boron Waste (CBW) on asphalt samples was investigated. As a result of Marshall Design Method, it has been proved that boron wastes can be used in asphalt concrete within the specification limits. Besides, an artificial neural network (ANN) model was created for the evaluation of obtained data. As a result of Marshall Design Method, it has been proved that boron wastes can be used in asphalt concrete within the specification limits. Furthermore, regarding the examination of modelling and statistical analysis, the mechanical performance of asphalt concrete samples with and without CBW addition has been predicted in a noticeable manner. As a result of regression analysis, training and test sets $\mathrm{r}^{2}$ values are reached $0.95-0.91$ for stability and $0.91-0.87$ for flow values. Finally, a simulation was prepared with the created model, and the effect of boron wastes on asphalt samples was examined in more detail.
\end{abstract}

Keywords: Marshall test; Asphalt concrete; Boron waste; Artificial neural networks; Recycling; Sustainability.

\section{INTRODUCTION}

The public, industry, and governments have become increasingly interested in green design and engineering as approaches towards better environmental quality and sustainable development. Pavement construction is one of the largest consumers of natural resources. Recycling of pavements represents an important opportunity to save the mining and use of virgin materials, conserve energy, divert materials away from landfills, and save money (Horvath, 2003). The use of recycled materials, instead of virgin materials, helps ease landfill pressures and reduce demand of extraction. This is one way of getting the road construction industry on track towards sustainable construction practices (Huang at al., 2007). Countries with boron reserves have seriously been suffering from boron waste heaps in recent years. Turkey has $72 \%$ of the world's boron reserves (Banar et al., 2017), which led to formation of the world's largest boron waste heaps, and waste storages built as a consequence occupy a significant place in the country (Figure 1). 250,000 tons of concentrator waste as well as 150,000 tons of boron derivative waste is formed yearly in 
Eskisehir, Kirka (Karasu at al., 2002). When these wastes are discharged to waste ponds and seas, they can cause damage on agricultural irrigation, groundwater, aquatic life, and plants. Furthermore, waste stacks and storage problems occur near mine sites. However, these wastes can be evaluated in the road construction in the vicinity and can be disposed of in a short time (Selman, 2015). There are many in this field who use these wastes as an element of construction material such as floor tile body and wall square, bricks, ceramics, cement, and concrete production. In addition, since the early 2000s, boron wastes have also been used in asphalt production researches (Keskin and Karacasu, 2019).

One of the main objectives of this study is to estimate the mechanical properties (stability and flow values) of asphalt samples with and without additives. Stability and flow values can be calculated with Marshall Test. The Marshall Test concept was developed by Bruce Marshall. In 1948, The U.S. Corps of Engineers improved the Marshall Test procedure, added specific properties, and consequently developed the mix design criteria (The Asphalt Institute, 1988). This method consists of a series of tests carried out to determine the Optimum Bitumen Content $(\mathrm{OBC})$ to be used in asphalt concrete. It allows obtaining information on the stability, flow, and specimen characteristics of the bituminous mixtures. Samples are compacted with a hammer (weight of $4.536 \mathrm{~kg}$ ) by a certain number of free falls on two faces of the bituminous mixture from height of $45.7 \mathrm{~cm}$ (Karacasu, 2016). The number of free falls for low and mid-traffic volume roads is 50 for both faces, while for high-traffic volume roads this figure is 75 blows. This technique is used to measure the resistance of samples against permanent deformation at a constant speed of $50 \mathrm{~mm} / \mathrm{min}$ and $60^{\circ} \mathrm{C}$ temperature (Tapkin, 1998). Marshall Test technique is widely accepted by all of the research laboratories worldwide (Tapkin and Keskin, 2018).

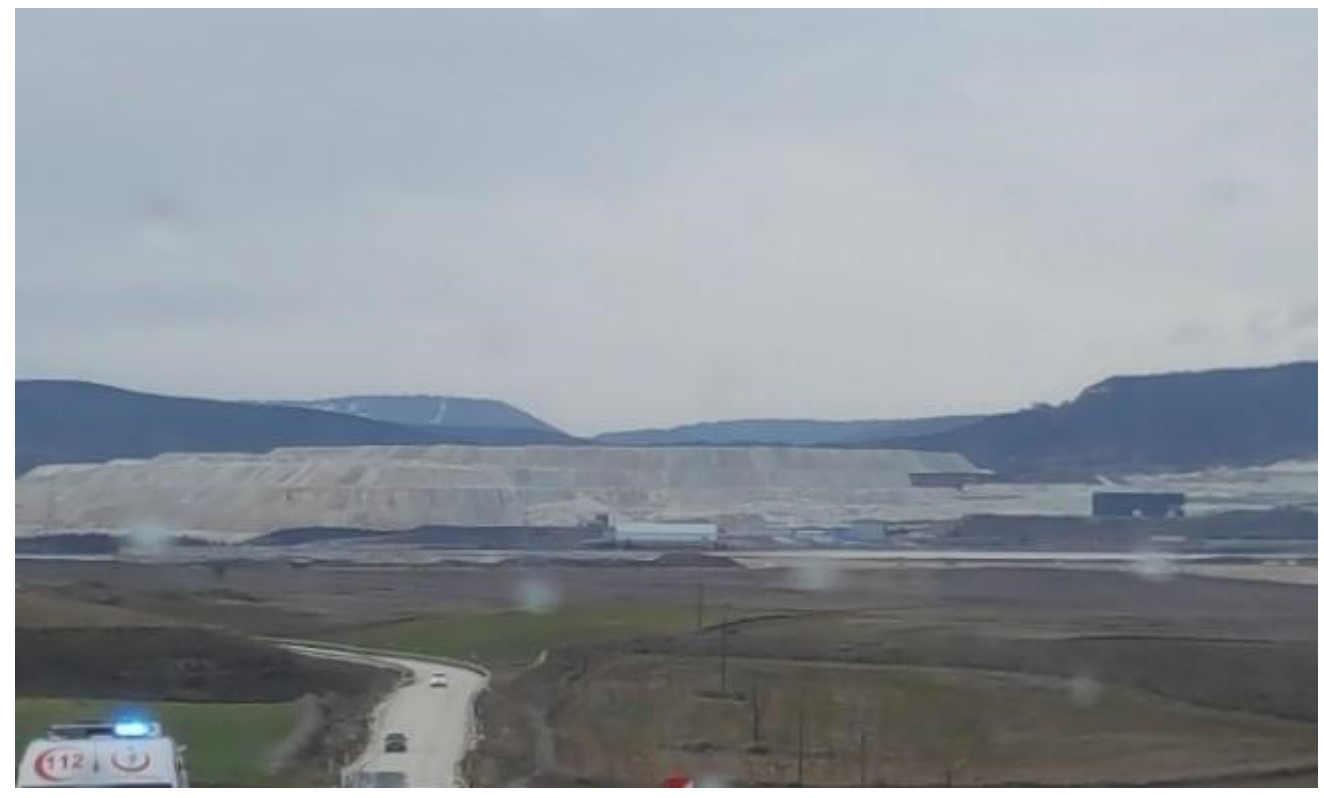

Figure 1. Boron waste field (Keskin and Karacasu, 2019).

Artificial neural networks are computer systems that can produce new information by learning from the characteristics of the human brain. While the learning process in the human brain is carried out with biological neurons, computer systems perform this process with artificial neurons. Chemical reactions that start with dendrites in biological neurons are transmitted to the synapses through the axons and are interpreted in synapses. In artificial neural networks, there are a data input layer that acts as a dendrite, hidden layers acting as axons, and finally an output layer, where the resulting values are taken instead of synapses. 
The input layer is the part where initial data (inputs) are entered into network for the problem that neural network operates. The number of neurons in this layer is equal to the number of input parameters of the problem, and each neuron contains data related to the input (Veelenturf, 1995). This data must be entered numerically in the input layer. The hidden layer is the actual processing layer of artificial neural network. This layer is expressed as hidden because it is not seen by the user. It is the layer in which data received from the input layer is processed with a proper function to the related problem and transmitted to output layer to obtain the result data. The network designer has control over whether there will be hidden layer within the network or how many layers the network will be in, and it is determined by the problem being addressed. The output layer is the part where data is processed with a function appropriate to network structure, and the system results are presented as output data. Similar to relationship in input layer, the number of neurons in output layer is equal to the number of outputs expected from the network (Akkurt, 2005).

When the history of ANN is examined, it should be divided into two main sections as before and after 1980 . Studies before 1980 were first put forward in 1890 and progressed heavily until computer technologies developed. ANN has become able to be used in daily life after 1980s rapidly. Very detailed information about the computer system applications of pavement engineering, which has been carried out until 2010, can be found in the relevant literature (Tapkin at al., 2010). There are many studies on neural networks after 2010. In two studies conducted by Turan at al. (2011a, 2011b), ANN based classification technique was applied for the prediction of percentage adsorption efficiency for the removal of $\mathrm{Zn}$ (II) ions from leachate by hazelnut shell and for the removal of $\mathrm{Cu}$ (II) ions from industrial leachate by pumice. Ozgan (2011) predicted the stability values of asphalt concretes, and Zofka and Yut (2012) predicted the creep compliance values of asphalt binder with ANN. In 2014, Ozturk and Emin Kutay (2014) created a new ANN model for Superpave asphalt mixture design; also, Shafabakhsh at al. (2015) generated an ANN for rutting performance of nano-modified asphalt concretes. In 2017, Mirabdolazimi and Shafabakhsh (2017) estimated the rutting depths of the FORTA fiber modified asphalt concrete samples with neural networks and genetic programming techniques. Ahmed at al. (2017) predicted fatigue performance of hot mix asphalt using ANN. Kara and Karacasu (2017) examined of waste ceramic tile additive in hot mix asphalt using fuzzy logic application. The first of the three different studies conducted in 2018 was to optimize the asphalt mix design by using ANN and genetic algorithm (Sebaaly at al., 2018); the second one was the quasi-static analysis of flexible pavements based on predicted frequencies using Fast Fourier Transform and ANN (Ghanizadeh and Fakhri, 2018). Finally, Jiang at al. (2018) worked on characterization of asphalt mixtures, which have been identified by convolutional neural network methods using x-ray scan images. Majidifard at al. (2019) presented innovative machine learning methods called gene expression programming (GEP) and hybrid artificial neural network/simulated annealing (ANN/SA) to predict the fracture energy of asphalt mixture specimens. Moniri at al. (2020) invested the ANN model for cracking of HMA in terms of temperature and reclaimed asphalt pavement (RAP) and fiber content, and they said that both investigated models were appropriate for predicting the cracking behavior of fiber-reinforced recycled asphalt mixtures. Nevertheless, the level of correlation was much higher for the ANN approach than the multiple regression model. Ullah at al. (2020) developed an ANN-based model to predict permanent deformation of base course containing RAP. Finally, according to Alas at al. (2020), ANN and ANFIS models for predicting the outcomes of the DSR test results had been shown to provide reliable models both with training and testing data sets. Finally Samba at al., (2021) worked on a new mathematical and artificial neural network (ANN), which were developed for Libyan crudes and compared with renowned dead oil viscosity correlations. Developed ANN model and mathematical model gave the lowest error when they compared with different empirical correlations.

As it is seen, there is no computer modelling technique that has been created with boron wastes so far. In this study, the physical and mechanical properties of asphalt concrete samples prepared with the modification of CBW were investigated. The stability and flow values of the samples were estimated with the ANN model formed by the physical properties of these samples. 


\section{TEST PROGRAM}

\section{Material Properties}

In this study, 50/70 penetration bitumen obtained from Izmit Tupras refinery was used as bitumen. Limestone was preferred as aggregate; it is within the range of TYPE-1 gradation limits for wearing course set by Highway Technical Specifications of General Directorate of Turkish Highways (Highway Technical Specifications, 2013). Physical properties of aggregates are given in Table 1, the mixture gradation and gradation limits are given in Figure 2, rheological properties of bitumen are given in Table 2, and the physical properties of the CBW used in the experimental program are given in Table 3. Boron wastes exist in the form of lumps in the nature and pollute the nature in this form. These wastes are turned into the state given in Figure 3 after being crushed 30 minutes with the Los Angeles test apparatus. When the gradation of the crushed material was examined, it was seen that most of the material passed through the $1.18 \mathrm{~mm}$ sieve. For recycling the material as much as possible, all of the material under $1.18 \mathrm{~mm}$ sieve was stocked for use in the experiments.

Table 1. Physical properties of aggregates.

\begin{tabular}{|c|c|c|c|}
\hline Properties & & Values & Standard \\
\hline \multirow{4}{*}{ Coarse Aggregate } & Apparent Specific Gravity $\left(\mathrm{gr} / \mathrm{cm}^{3}\right)$ & 2,688 & \multirow{4}{*}{ ASTM C127 } \\
\hline & Bulk Specific Gravity (gr/cm³) & 2,745 & \\
\hline & Bulk SSD Specific Gravity $\left(\mathrm{gr} / \mathrm{cm}^{3}\right)$ & 2,709 & \\
\hline & Water Absorption (\%) & 0.77 & \\
\hline \multirow{4}{*}{ Fine Aggregate } & Apparent Specific Gravity $\left(\mathrm{gr} / \mathrm{cm}^{3}\right)$ & 2,618 & \multirow{4}{*}{ ASTM C128 } \\
\hline & Bulk Specific Gravity $\left(\mathrm{gr} / \mathrm{cm}^{3}\right)$ & 2,729 & \\
\hline & Bulk SSD Specific Gravity $\left(\mathrm{gr} / \mathrm{cm}^{3}\right)$ & 2,659 & \\
\hline & Water Absorption (\%) & 1.58 & \\
\hline Filler & Specific gravity $\left(\mathrm{gr} / \mathrm{cm}^{3}\right)$ & 2,688 & ASTM C128 \\
\hline
\end{tabular}

In this study, 50/70 penetration bitumen obtained from Izmit Tupras refinery was used as bitumen. Limestone was preferred as aggregate; it is within the range of TYPE-1 gradation limits for wearing course set by Highway Technical Specifications of General Directorate of Turkish Highways (Highway Technical Specifications, 2013). Physical properties of aggregates are given in Table 1, the mixture gradation and gradation limits are given in Figure 2, rheological properties of bitumen are given in Table 2, and the physical properties of the CBW used in the experimental program are given in Table 3. Boron wastes exist in the form of lumps in the nature and pollute the nature in this form. These wastes are turned into the state given in Figure 3 after being crushed 30 minutes with the Los Angeles test apparatus. When the gradation of the crushed material was examined, it was seen that most of the material passed through the $1.18 \mathrm{~mm}$ sieve. For recycling the material as much as possible, all of the material under $1.18 \mathrm{~mm}$ sieve was stocked for use in the experiments. 


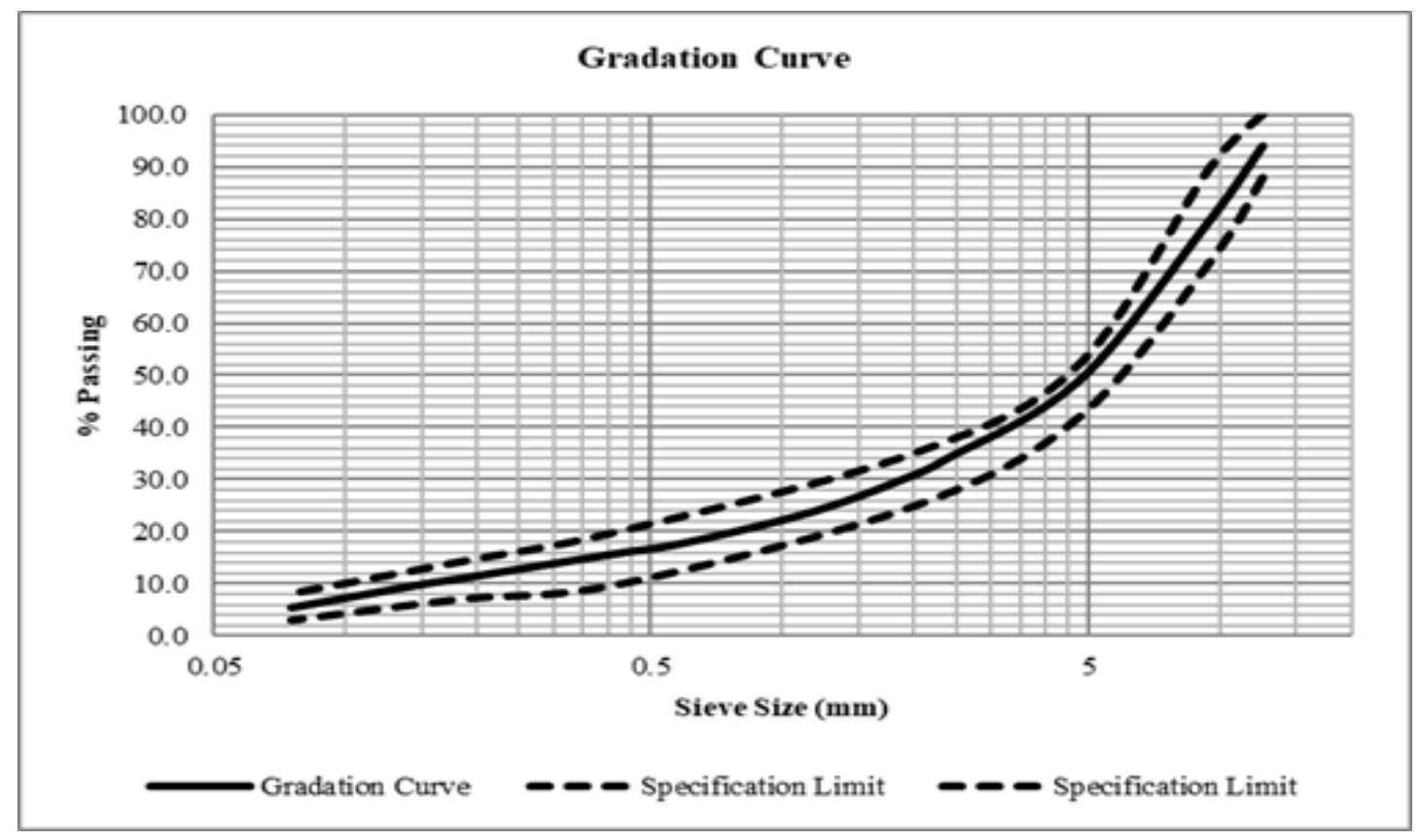

Figure 2. Gradation Curve and Type 1 wearing course gradation (Highway Technical Specifications, 2013).

Table 2. Rheological properties of bitumen.

\begin{tabular}{|c|c|c|}
\hline Experiment & Value & Standards \\
\hline Penetration $\left(25^{\circ} \mathrm{C}\right)$ & $64(50 / 70)$ & ASTM D5 \\
\hline Softening Point $\left({ }^{\circ} \mathrm{C}\right)$ & 48 & ASTM D36/D36M-09 \\
\hline Specific Gravity $\left(\mathrm{gr} / \mathrm{cm}^{3}\right)$ & 1,028 & ASTM D70-09e1 \\
\hline Ductility $\left(25^{\circ} \mathrm{C}, 5 \mathrm{~cm} / \mathrm{min}^{3}\right)$ & $>100 \mathrm{~cm}$ & ASTM D113-07 \\
\hline Loss on Heating $(\%)$ & 0.43 & ASTM D6-95 \\
\hline Flash Point $\left({ }^{\circ} \mathrm{C}\right)$ & 314 & ASTM D92-05a \\
\hline Viscosity $\left(\right.$ at $\left.135^{\circ} \mathrm{C}, \mathrm{cP}\right)$ & 437.5 & ASTM D4402-06 \\
\hline Viscosity $\left(\right.$ at $\left.165^{\circ} \mathrm{C}, \mathrm{cP}\right)$ & 137.5 & ASTM D4402-06 \\
\hline
\end{tabular}


Table 3. Physical properties of boron waste.

\begin{tabular}{|c|c|}
\hline Physical Property & Value \\
\hline Loose bulk density, gr/cm ${ }^{3}$ & 1.086 \\
\hline Compacted bulk density, gr/cm ${ }^{3}$ & 1.263 \\
\hline Color & Cream \\
\hline Specific Gravity, gr/cm ${ }^{3}$ & 1.161 \\
\hline
\end{tabular}

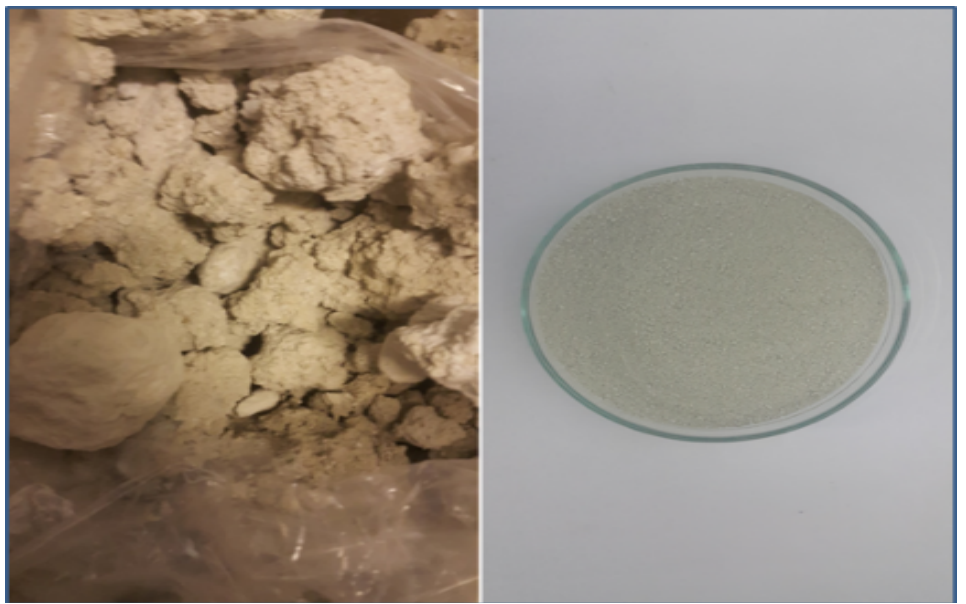

Figure 3. Crushed Boron Waste (CBW).

\section{Mixture Formula}

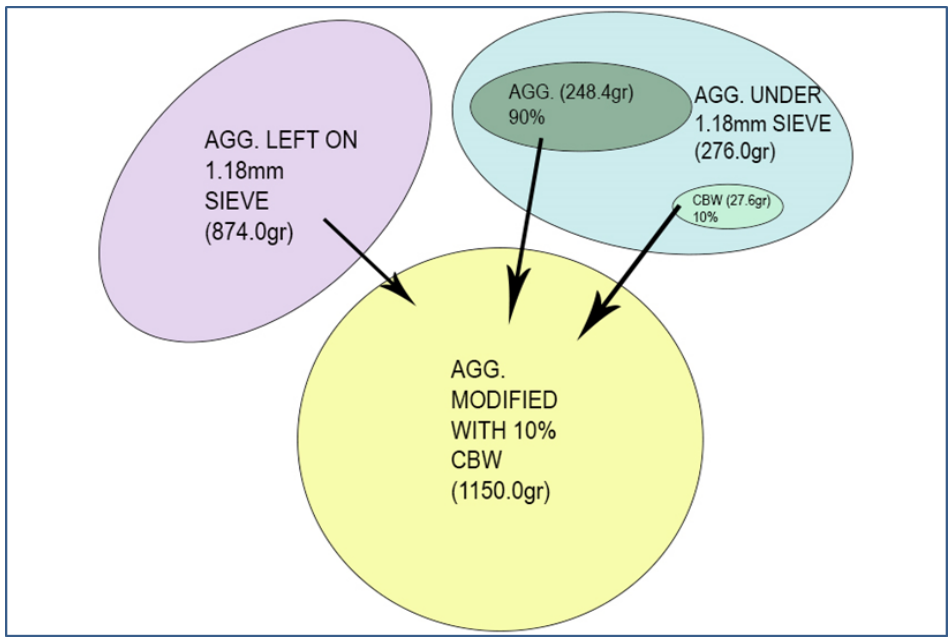

Figure 4. Aggregates modified with $10 \% \mathrm{CBW}$. 


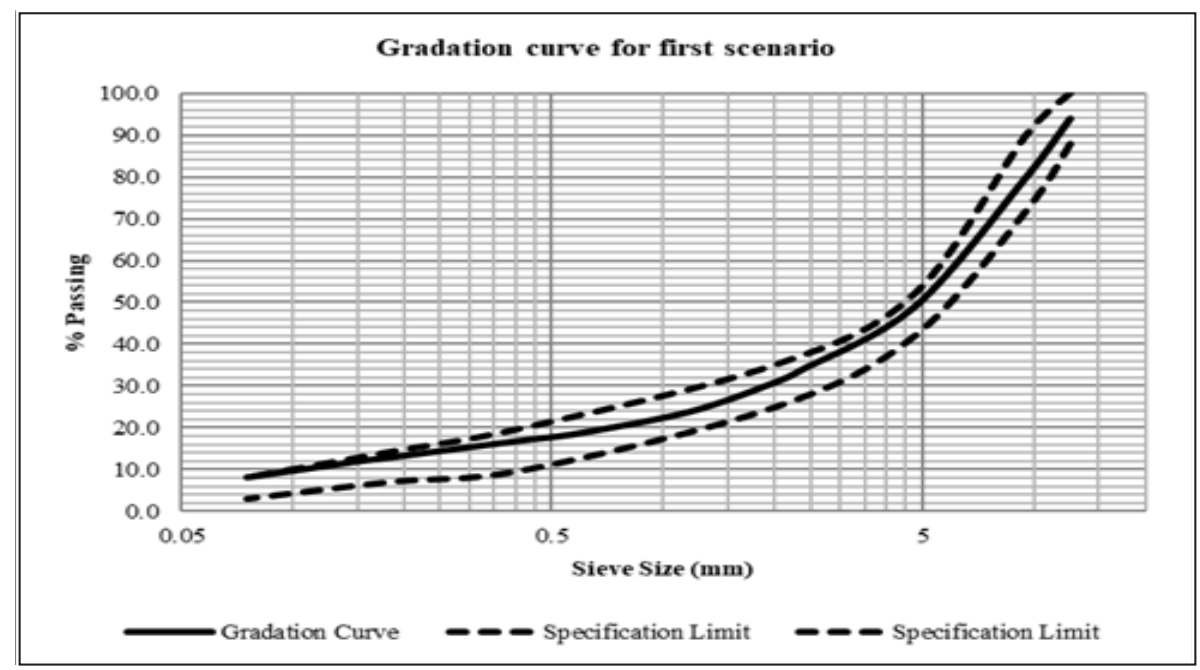

Figure 5. Gradation curve for first scenario.

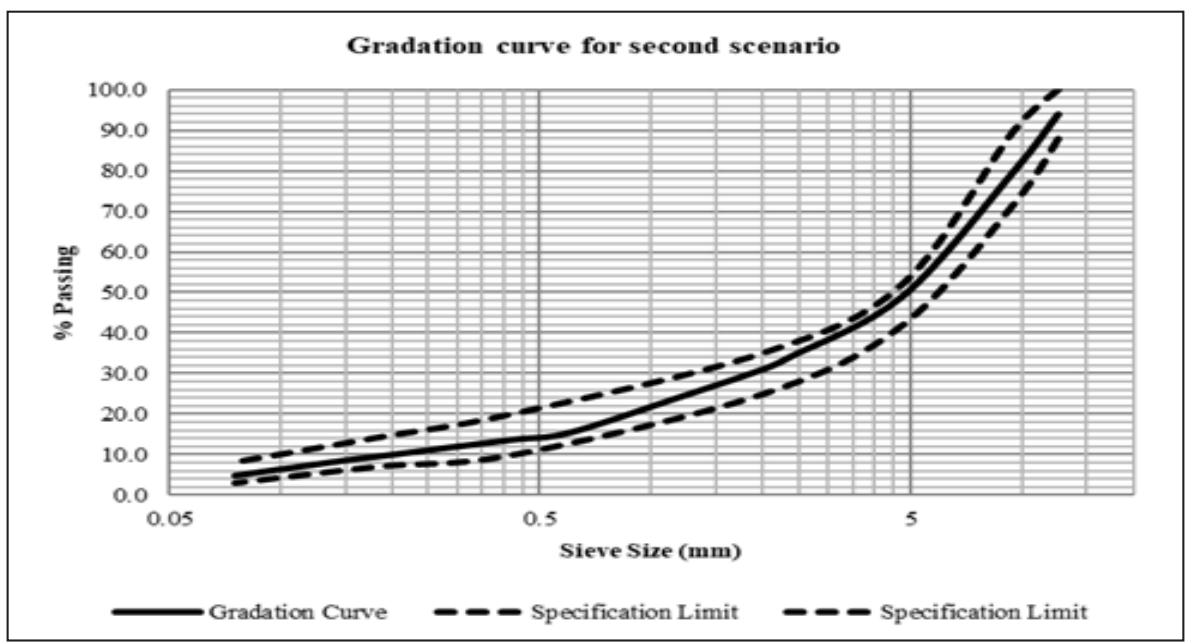

Figure 6. Gradation curve for second scenario.

Samples of asphalt concrete were prepared with Marshall Test method. The aggregate and bitumen constituting mixtures were kept in the oven at $160^{\circ} \mathrm{C}$, and the preferred mixture temperature was $135^{\circ} \mathrm{C}$. The mixtures prepared with $1150 \mathrm{gr}$ aggregate and with a bitumen rate used with an increase of $0.5 \%$ between $3.5 \%$ and $6.5 \%$ are compacted with 75 blows for heavy traffic volume roads. Modification was prepared by CBW materials replacing the aggregates under $1.18 \mathrm{~mm}$ sieve by weights of $5 \%, 10 \%$, and $15 \%$. For example, 27.6 grams of CBW and 248.4gr aggregates were used instead of 276 grams aggregates under $1.18 \mathrm{~mm}$ sieve for $10 \%$ additive rate (Figure 4 ). The gradation of modified samples must be discussed before the studies continue. CBW materials were used in studies $15 \%$ at most, which concerned authors on how gradation is affected after adding waste materials. The authors created two scenarios by $15 \%$ additive rate; first, all materials that passed $1.18 \mathrm{~mm}$ sieve are considered filler material; second, all materials are to be of $0.6 \mathrm{~mm}$ grain size, which is the next sieve after $1.18 \mathrm{~mm}$ sieve. In both scenarios, the gradation of modified aggregates had been within specification limits shown in Figures 5 and 6. 


\section{Marshall Test Results}

Marshall test results are discussed in this part. The average physical and mechanical properties of the prepared asphalt concrete samples (100 pieces) are given in Table 4. When the mechanical properties were examined in detail for all samples. Stability values of most of the samples were higher than specification limits $(900 \mathrm{~kg})$, and a large part of the flow values are within the limits again $(2-4 \mathrm{~mm})$. According to the optimum bitumen content calculations, specification values are provided in terms of strength. For physical properties, it can be seen that as the CBW ratio increases, the unit weight values of the mixtures decrease, and the air voids increase. The figure prepared with the MATLAB ("MATLAB Version R2015a," 2015) (Figure 7) shows the bitumen content, CBW content, and stability relationship. As the CBW ratio increases, the stability values of the samples decrease, but the highest values are observed at the rate of $10 \% \mathrm{CBW}$ additive when the boron wastes are examined among themselves. Especially in low bitumen ratios (3.5-4.5), low stability values are obtained in samples with 5\% and $15 \%$ additives, but $10 \%$ additives give higher values. Besides, the air void (Va) values from the physical properties of the samples are examined in more detail. The CBW additive increases the Va values shown in Figure 8. The air void values at 5\% and $10 \%$ additive rates show a slight increase compared to the control samples; however, at $15 \%$ Va values have increased considerably. Depending on the air void ratio, the voids in mineral aggregate (V.M.A.) and the voids filled with asphalt (Vf) values decrease as voids increase.

Table 4. Average physical and mechanical properties of the prepared asphalt concrete samples.

\begin{tabular}{|c|c|c|c|c|c|c|c|c|}
\hline $\begin{array}{c}\text { Bitumen } \\
\text { Content } \\
(\%)\end{array}$ & $\begin{array}{c}\text { Specimen } \\
\text { Height } \\
\text { (mm) }\end{array}$ & $\begin{array}{c}\text { V.M.A } \\
(\%)\end{array}$ & Vf $(\%)$ & Va (\%) & $\begin{array}{c}\text { Unit } \\
\text { Weight } \\
\left(\mathrm{kg} / \mathrm{m}^{3}\right)\end{array}$ & $\begin{array}{c}\text { CBW } \\
\text { Content } \\
(\%)\end{array}$ & $\begin{array}{c}\text { Stability } \\
\text { (kg) }\end{array}$ & $\begin{array}{l}\text { Flow } \\
(\mathbf{m m})\end{array}$ \\
\hline 3.5 & 61.42 & 13.87 & 57.39 & 5.96 & $2,403.78$ & 0 & $1,685.25$ & 2.48 \\
\hline 4 & 60.81 & 13.45 & 67.55 & 4.37 & $2,427.10$ & 0 & $1,712.43$ & 1.81 \\
\hline 4.5 & 60.74 & 13.19 & 77.7 & 2.95 & $2,446.11$ & 0 & $1,747.72$ & 2.57 \\
\hline 5 & 60.37 & 12.77 & 89.65 & 1.32 & $2,469.93$ & 0 & $1,579.89$ & 2.5 \\
\hline 5.5 & 60.25 & 13.03 & 96.27 & 0.49 & $2,474.06$ & 0 & $1,374.90$ & 3.28 \\
\hline 6 & 61.22 & 13.95 & 97.17 & 0.4 & $2,459.72$ & 0 & $1,061.26$ & 5 \\
\hline 6.5 & 61.38 & 14.67 & 99.18 & 0.12 & $2,450.53$ & 0 & 997.68 & 4.34 \\
\hline 3.5 & 62 & 14.17 & 55.64 & 6.29 & $2,395.42$ & 5 & $1,157.68$ & 3.18 \\
\hline 4 & 61.68 & 13.59 & 66.86 & 4.52 & $2,423.33$ & 5 & $1,205.35$ & 4.99 \\
\hline 4.5 & 60.8 & 13.27 & 77.13 & 3.04 & $2,443.85$ & 5 & $1,545.53$ & 2.96 \\
\hline 5 & 60.05 & 12.8 & 89.34 & 1.37 & $2,468.85$ & 5 & $1,511.06$ & 2.86 \\
\hline 5.5 & 60.5 & 12.99 & 96.64 & 0.44 & $2,475.33$ & 5 & $1,347.71$ & 3.38 \\
\hline 6 & 61.06 & 13.74 & 98.84 & 0.16 & $2,465.71$ & 5 & $1,126.84$ & 4.53 \\
\hline
\end{tabular}




\begin{tabular}{|c|c|c|c|c|c|c|c|c|}
\hline $\mathbf{6 . 5}$ & 61.53 & 14.81 & 98.09 & 0.28 & $2,446.52$ & 5 & 898.05 & 4.74 \\
\hline $\mathbf{3 . 5}$ & 61.5 & 14.23 & 55.36 & 6.36 & $2,393.75$ & 10 & $1,199.03$ & 2.93 \\
\hline $\mathbf{4}$ & 61.04 & 13.52 & 67.25 & 4.44 & $2,425.31$ & 10 & $1,583.27$ & 2.36 \\
\hline $\mathbf{4 . 5}$ & 61.99 & 13.75 & 74.06 & 3.57 & $2,430.45$ & 10 & $1,514.03$ & 3.55 \\
\hline $\mathbf{5}$ & 60.42 & 13.17 & 86.55 & 1.78 & $2,458.61$ & 10 & $1,455.75$ & 3.05 \\
\hline $\mathbf{5 . 5}$ & 60.6 & 13.59 & 91.7 & 1.13 & $2,458.11$ & 10 & $1,374.36$ & 3.94 \\
\hline $\mathbf{6}$ & 61.23 & 13.88 & 97.64 & 0.33 & $2,461.48$ & 10 & $1,075.64$ & 4.15 \\
\hline $\mathbf{6 . 5}$ & 61.37 & 14.78 & 98.34 & 0.25 & $2,447.47$ & 10 & 961.95 & 5.74 \\
\hline $\mathbf{3 . 5}$ & 62.49 & 15.68 & 49.39 & 7.94 & $2,353.25$ & 15 & $1,063.14$ & 1.61 \\
\hline $\mathbf{4}$ & 61.6 & 14.66 & 61.09 & 5.7 & $2,393.31$ & 15 & $1,156.35$ & 2.65 \\
\hline $\mathbf{4 . 5}$ & 61.59 & 14.43 & 69.99 & 4.33 & $2,411.12$ & 15 & $1,254.16$ & 2.15 \\
\hline $\mathbf{5}$ & 61.64 & 14.23 & 79.17 & 2.98 & $2,428.60$ & 15 & $1,202.66$ & 2.86 \\
\hline $\mathbf{5 . 5}$ & 60.7 & 13.75 & 90.55 & 1.31 & $2,453.62$ & 15 & $1,130.86$ & 2.73 \\
\hline $\mathbf{6}$ & 61.06 & 14.15 & 95.52 & 0.63 & $2,453.97$ & 15 & 988.05 & 3.47 \\
\hline $\mathbf{6 . 5}$ & 61.49 & 15.03 & 96.42 & 0.54 & $2,440.26$ & 15 & 847.38 & 4.36 \\
\hline
\end{tabular}

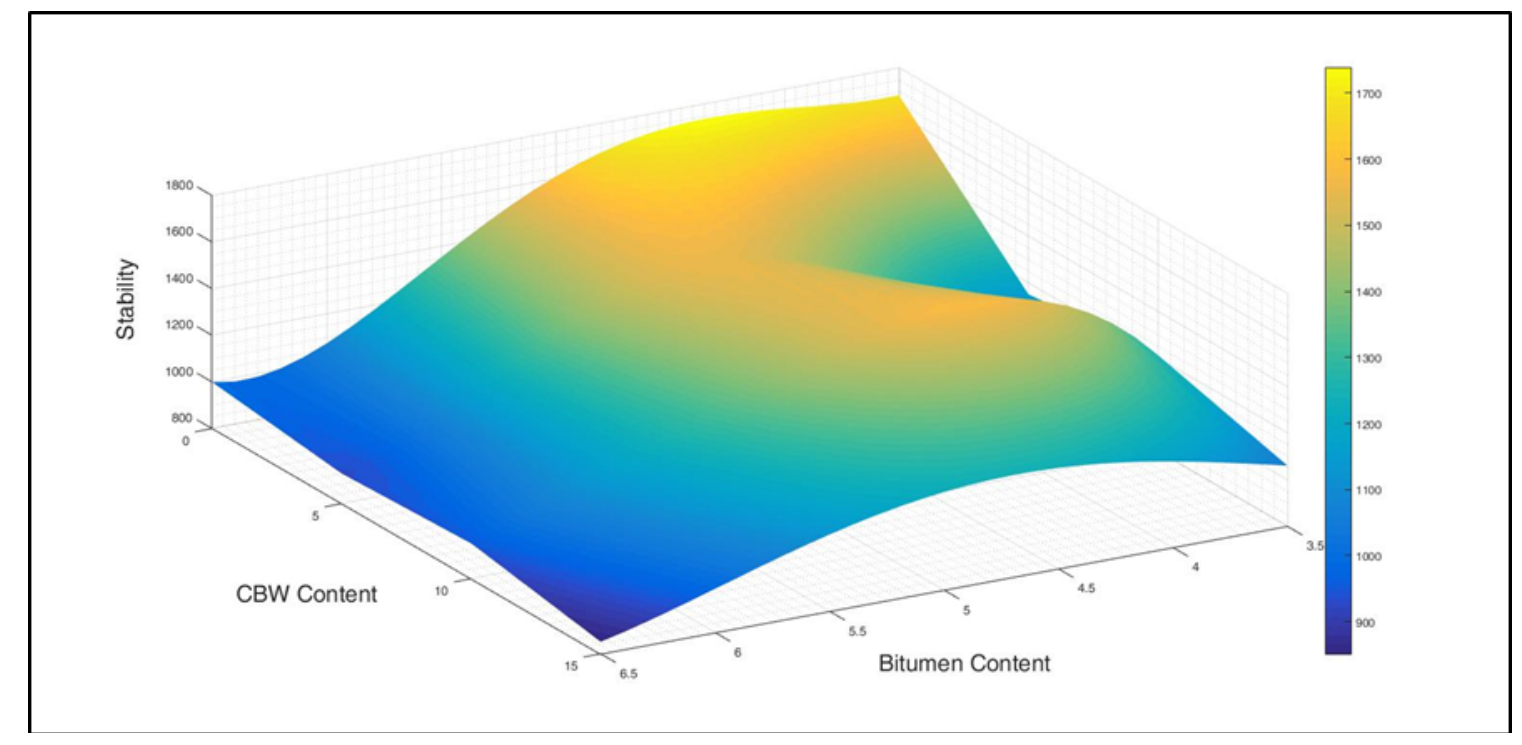

Figure 7. Surface maps related to Stability depend on bitumen content and CBW content. 


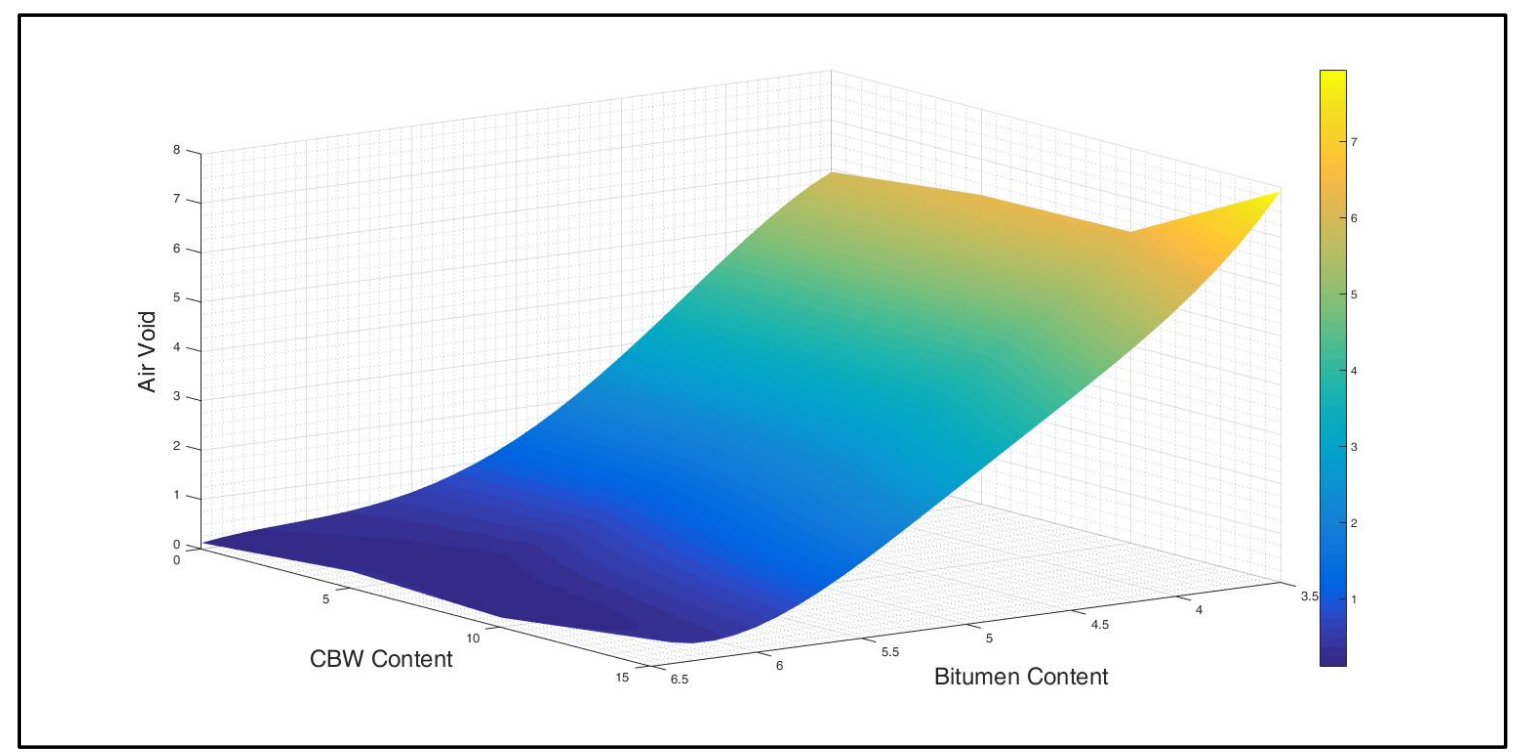

Figure 8. Surface maps related to air void depend on bitumen content and CBW content.

The main goal of the Marshall design procedure is to calculate the OBC. In order to calculate this value, the designer must be able to draw the data curves of the following specifications.

- Maximum stability

- Maximum unit weight

- Va value stated by specification

- Vf value stated by specification.

The average of these four values calculated with the drawn data curves gives the OBC. In this study, the Va value was taken as $4 \%$, and the Vf value was as $70 \%$. Table 5 shows the OBC values calculated in the study. When Table 5 is analyzed, it can be found that $\mathrm{OBC}$ values are increasing as the boron waste ratio increases.

Table 5. Optimum bitumen content (OBC) values.

\begin{tabular}{|c|c|}
\hline Material & (OBC) (\%) \\
\hline Control & 4,34 \\
\hline \%5 CBW & 4,59 \\
\hline \%10 CBW & 4,66 \\
\hline \%15 CBW & 4,92 \\
\hline
\end{tabular}

OBC calculation is a method that requires long time and quality workmanship. At the end of the experiment, only stability and flow values can be calculated by damaging the samples. The specific gravity of mixture, theoretical specific gravity, V.M.A., Vf, and Va are obtained by carrying out extra calculations (Tapkin et al., 2010). Firstly, this 
study tries to prevent environmental pollution by using waste boron in asphalt production. According to the calculation, 86 tons of boron waste will be recycled in the context of sustainability in $1 \mathrm{~km}$ road production (Keskin and Karacasu, 2018). The second aim of the study is to estimate the stability and flow values without damaging the asphalt samples with neural networks. In this way, after the samples have been compacted, OBC values can be found with extra calculations only. Furthermore, time will be saved, and pavement engineers will be assisted directly.

\section{ARTIFICIAL NEURAL NETWORK STUDIES}

\section{Optımum Ann Model Selection And Neural Network Architecture}

There are two main sources of interest in artificial neural networks:

a) The desire to understand the working principles of the human brain.

b) Passion for building machines with the ability to successfully complete complex operations (Müller at al., 1990).

In ANN method, the strength of the interconnection was determined by weighting vector of NN (Rumelhart and McClelland, 1986). Each neuron performs two functions as shown below. The first is to sum all the inputs from lower layer based on their weighting factors as given in Eq. (1). The second is to process this sum by a nonlinear sigmoid function as shown in Eq. (2). The input and output neurons may not contain nonlinear functions. The basic Equations (1) and (2) describing the dynamics of each neuron were given as follows (Ozgan, 2011):

$$
\begin{gathered}
n e t_{j}=\sum_{i} W_{i j} o_{i} \\
o_{j}=f\left(\text { net }_{j}+\theta_{j}\right)
\end{gathered}
$$

where " $W_{i j}$ " is the weight between the jth neuron and the ith neuron in two adjacent layers, " $\theta_{j}$ " is the threshold of the jth neuron, " $O_{i}$ " is the output of the ith neuron, " $O_{J}$ " is the output of the jth neuron, and " $f($.$) " Is the Sigmoid$ function.

The performance of the artificial neural network mainly depends on the architecture of the network and the choice of inputs. In particular, the number of hidden layers, how many neurons will be in the layers, and which activation and transfer functions to use should be determined by different trials and long efforts. After all these choices have been made, the neural network undergoes a training process like the human brain and is tested after the training with examples that the network has never seen before. The proximity of the found values to the actual values determines the performance of network.

MATLAB NN Toolbox program was used in this study. The program can use the feedback training algorithms given in Table 6. As a result of long trials and different algorithms given in Table 6, "trainbr" algorithm has been determined as the most suitable option. Trainbr is a network training function that updates the weight and bias values according to Levenberg-Marquardt optimization. It minimizes a combination of squared errors and weights and then determines the correct combination so as to produce a network that generalizes well. The process is called Bayesian 
regularization ("MATLAB Version R2015a," 2015). Bayesian regularization minimizes a linear combination of squared errors and weights. It also modifies the linear combination, so that, at the end of training, the resulting network has good generalization qualities (MacKay, 1992; Dan Foresee and Hagan, 1997).

Table 6. Backpropagation training algorithms used in ANN training.

\begin{tabular}{|c|c|}
\hline MATLAB function name & Algorithm \\
\hline trainlm & Levenberg-Marquardt \\
\hline trainbr & Bayesian Regularization \\
\hline trainbfg & BFGS Quasi-Newton \\
\hline trainrp & Resilient Backpropagation \\
\hline trainscg & Scaled Conjugate Gradient \\
\hline traincgb & Conjugate Gradient with Powell/Beale Restarts \\
\hline traincgf & Fletcher-Powell Conjugate Gradient \\
\hline traincgp & Polak-Ribiére Conjugate Gradient \\
\hline trainoss & One Step Secant \\
\hline traingdx & Variable Learning Rate Gradient Descent \\
\hline traingdm & Gradient Descent with Momentum \\
\hline traingd & Gradient Descent \\
\hline traingda & Gradient descent with adaptive linear backpropagation \\
\hline
\end{tabular}




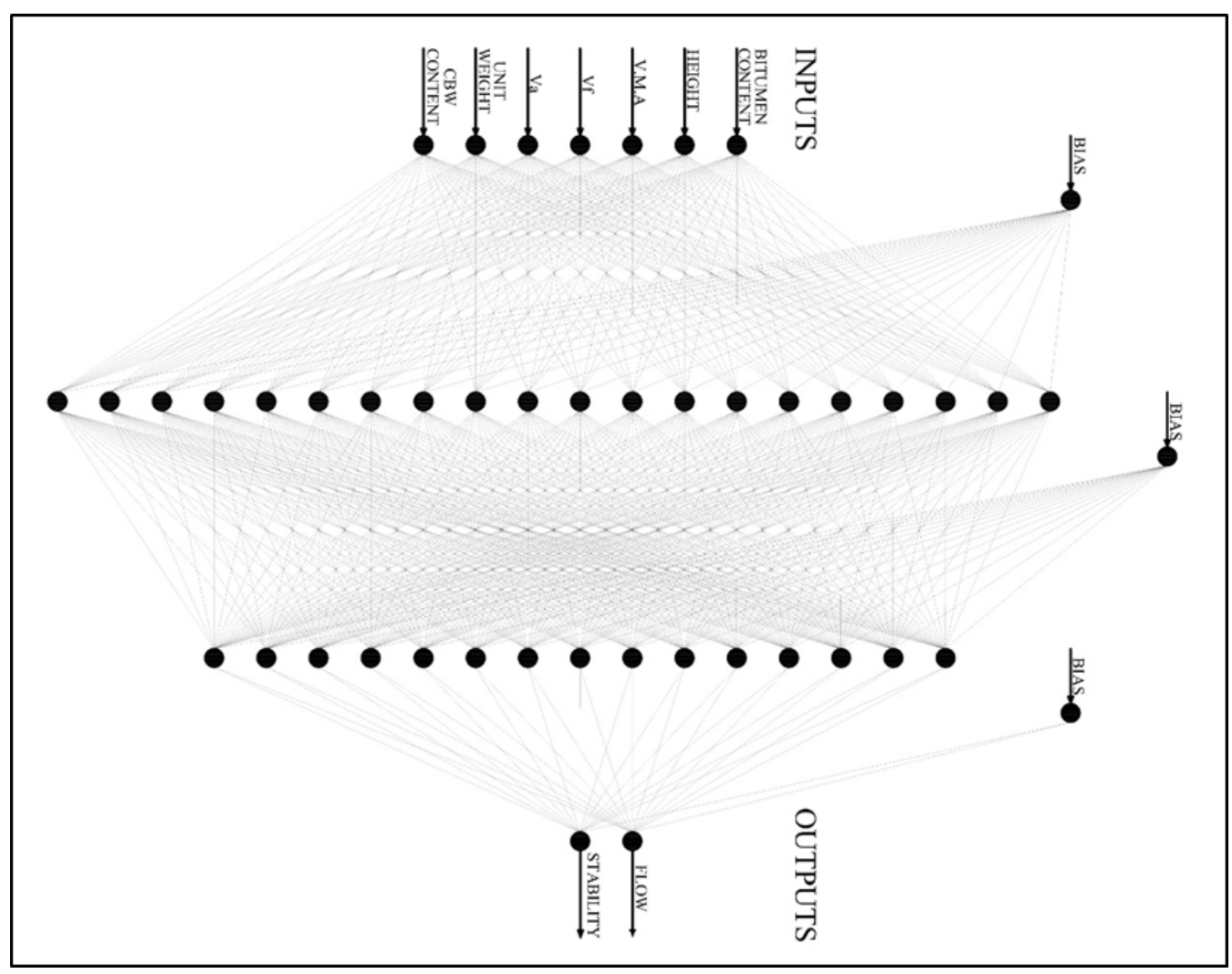

Figure 9. Developed ANN model architecture for the stability and flow of asphalt samples.

The design shown in Figure 9 is used as a neural network architecture (7-20-15-2). As seen, there are 7 neurons in the input layer. All of the inputs (BC, Height, V.M.A., Vf, Va, Unit Weight and CBW Content) were normalized with Eq. (3) between 0 and 1 values. Therefore, logarithmic Sigmoid function (Eq. (4)) is used as transfer function in each layer.

$$
F=\frac{F_{i}-F_{\min }}{F_{\max }-F_{\min }}
$$

where " $F$ " represents the normalized value, " $F$ " represents ith value of the measured values, and " $F_{\text {max }}$ " and " $F_{\min } "$ represent maximum and minimum values of the measured value (Ozgan, 2011).

$$
f(x)=\frac{1}{1+e^{-x}}
$$

Table 7 shows the descriptive statistics of the inputs. Data sets were randomly divided into $80 \%$ training set and $20 \%$ test set. The learning rate and momentum are the parameters that affect the speed of convergence of the backpropagation algorithm. A learning rate of 0.01 and momentum of 0.8 were fixed for selected network after training and model selection was completed for training set. 
Table 7. Descriptive statistics of inputs.

\begin{tabular}{|c|c|c|c|c|c|c|c|c|c|}
\hline $\begin{array}{c}\text { Descriptive } \\
\text { Statistics }\end{array}$ & $\begin{array}{c}\text { Bitumen } \\
\text { Content }\end{array}$ & Height & V.M.A & Vf & Va & $\begin{array}{c}\text { Unit } \\
\text { Weight }\end{array}$ & $\begin{array}{c}\text { CBW } \\
\text { Content }\end{array}$ & Stability & Flow \\
\hline Mean & 4.97 & 61.07 & 13.82 & 81.49 & 2.59 & $2,439.43$ & 6.06 & $1,319.90$ & 3.32 \\
\hline Standard Error & 0.11 & 0.08 & 0.09 & 1.79 & 0.26 & 3.39 & 0.65 & 33.83 & 0.13 \\
\hline Median & 5 & 61 & 13.71 & 87.89 & 1.57 & $2,446.83$ & 5 & $1,300.73$ & 3.23 \\
\hline Standard Deviation & 0.99 & 0.75 & 0.77 & 15.97 & 2.32 & 30.33 & 5.77 & 302.55 & 1.19 \\
\hline Sample Variance & 0.98 & 0.56 & 0.6 & 255.15 & 5.4 & 919.7 & 33.35 & $91,536.05$ & 1.41 \\
\hline Kurtosis & -1.24 & 2.28 & 0.25 & -1.1 & -0.6 & 1.39 & -1.37 & -1.04 & -0.27 \\
\hline Skewness & 0.04 & 0.8 & 0.63 & -0.52 & 0.72 & -1.2 & 0.33 & 0.25 & 0.43 \\
\hline Range & 3 & 4.65 & 3.64 & 52.08 & 8.41 & 137.48 & 15 & $1,151.49$ & 5.16 \\
\hline Minimum & 3.5 & 59.44 & 12.5 & 47.71 & 0.03 & $2,340.56$ & 0 & 808.01 & 1.29 \\
\hline Maximum & 6.5 & 64.09 & 16.14 & 99.79 & 8.44 & $2,478.03$ & 15 & $1,959.50$ & 6.45 \\
\hline Count & 80 & 80 & 80 & 80 & 80 & 80 & 80 & 80 & 80 \\
\hline
\end{tabular}

\section{Ann Outputs}

After the process of training modelled network, the performance of network was measured by test set. The results of Mean Absolute Error (MAE), Mean Squared Error (MSE), and Root Mean Squared Error (RMSE) analysis of the output values are given in Table 8, and the regression analysis curves are shown in Figures 10, 11, 12, and 13. The developed ANN displayed the best correlation with the experimental results for both training and testing sets. Enlightenment by statistical data has shown that modelling has been very successful. In particular, regression analyses prove the significance of the model. This is an indication that stability and flow values of control and CBW additive samples prepared under the same laboratory conditions can be measured without damaging the samples.

Table 8. Accuracy measure.

\begin{tabular}{|c|c|c|c|c|c|c|}
\hline & \multicolumn{3}{|c|}{ STABILITY } & \multicolumn{3}{c|}{ FLOW } \\
\hline & MAE & MSE & RMSE & MAE & MSE & RMSE \\
\hline TRAIN SET & 0.04296 & 0.00338 & 0.05814 & 0.05194 & 0.00462 & 0.06800 \\
\hline TEST SET & 0.06474 & 0.00632 & 0.07949 & 0.05816 & 0.00547 & 0.07395 \\
\hline
\end{tabular}




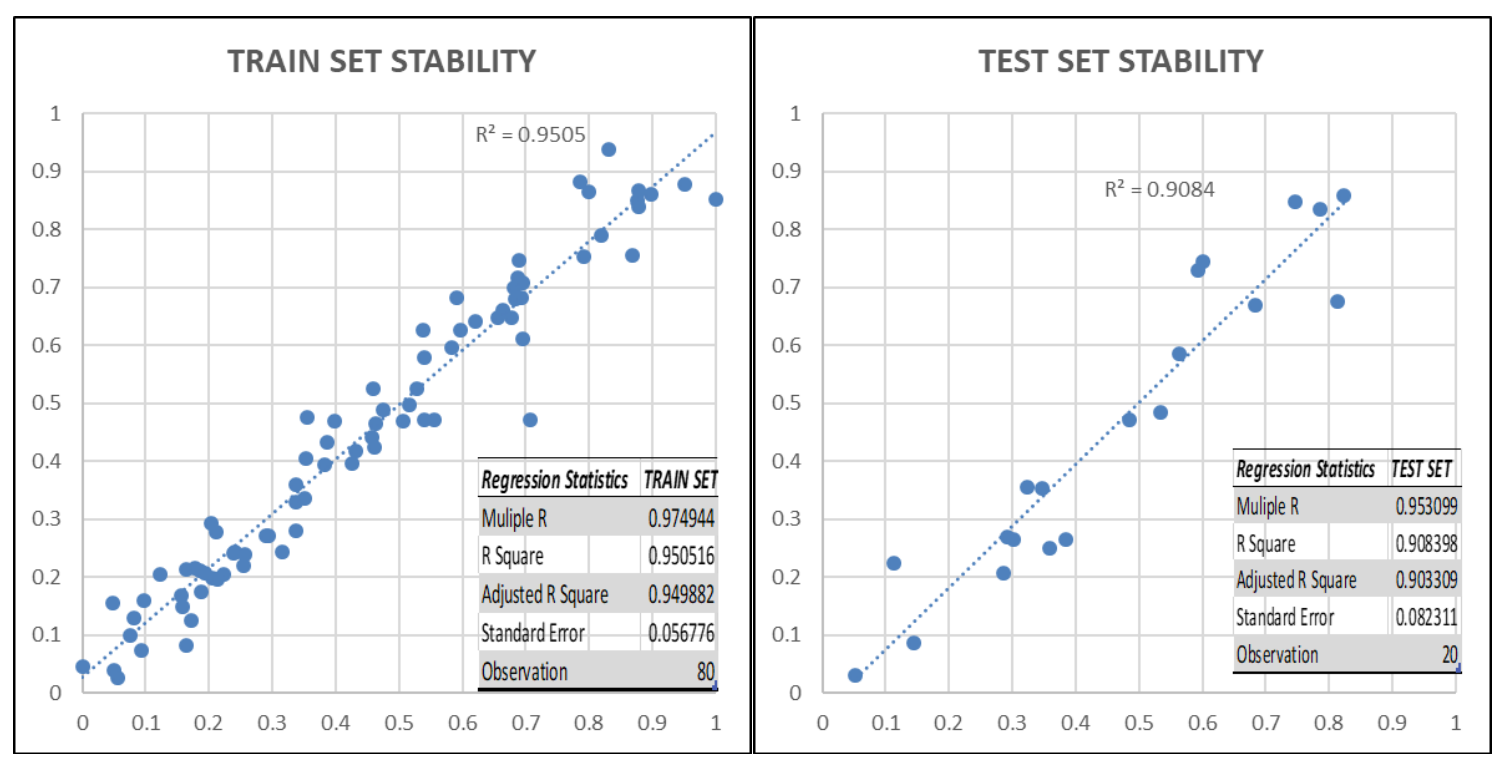

Figure 10. Regression statistics between experimental results and ANN model for training and test set (stability).

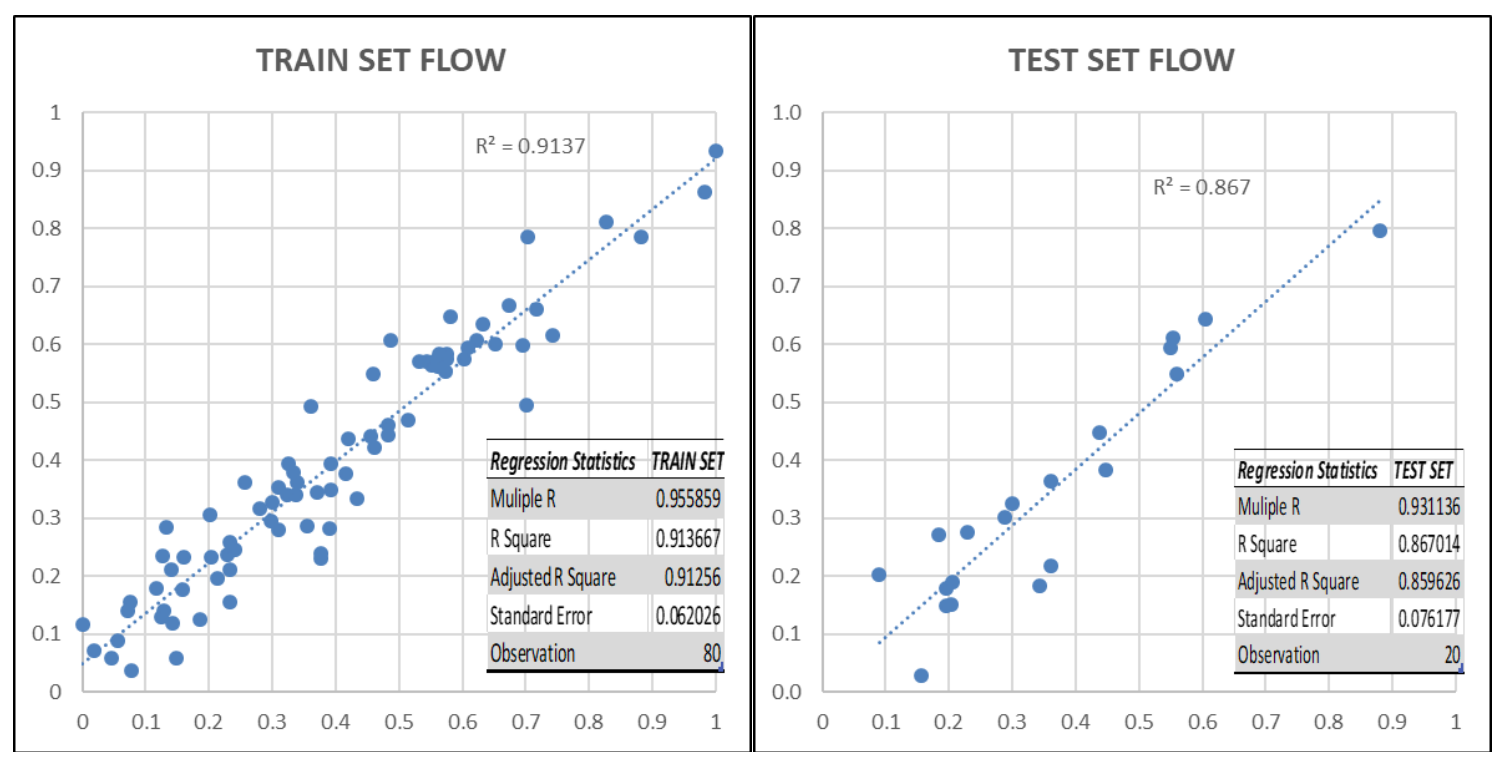

Figure 11. Regression statistics between experimental results and ANN model for training and test set (flow). 


\section{Simulation Results}
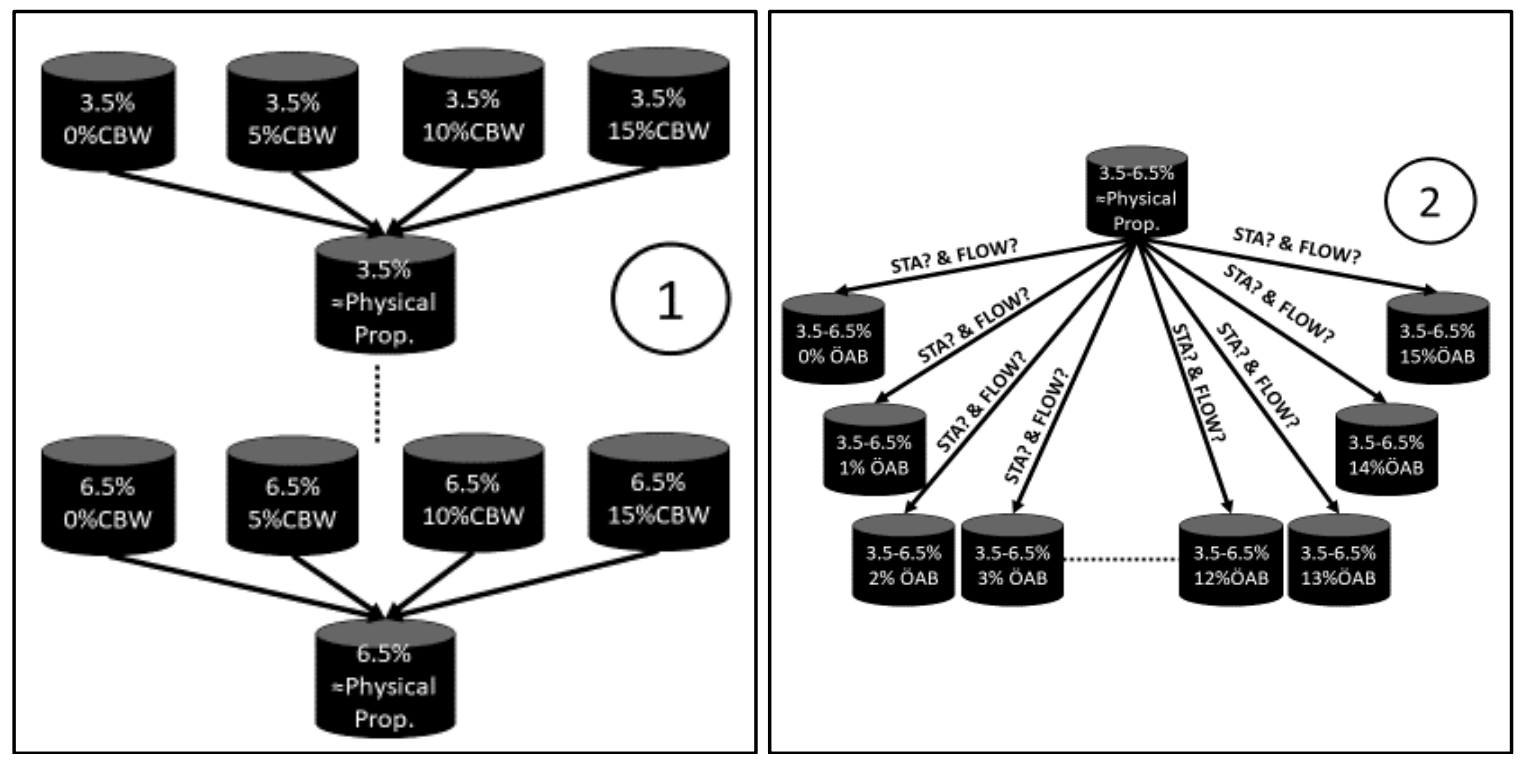

Figure 12. Simulation steps.

Finally, a simulation has been designed to investigate the effect of CBW modification on mechanical performance of asphalt concrete samples with the modelled ANN. According to the proposed scenario, stability and flow values were observed when the $\mathrm{BC}$ and $\mathrm{CBW}$ content ratios of the samples were changed with the identical physical properties (Height, V.M.A., Vf, Va, Unit Weight). Firstly, the average physical property values were calculated for each bitumen rate $(3.5,4,4.5,5,5.5,6.6 .5)$, and secondly, these values were processed into the created model, and the stability and flow values were simulated separately for each bitumen ratio and CBW ratio. The simulation steps are shown in Figure 12. The reader must understand that the physical properties should be different according to the CBW ratio, but the physical properties are assumed to be the identical in order to understand the effect of the CBW ratio on mechanical performance of samples. In this simulation, the physical properties corresponding to the percentage of each bitumen ratio were calculated separately. The generated graphs are given in Figures 13 and 14. With respect to Figure 13, if the stability values are examined in detail, the $10 \% \mathrm{CBW}$ content will particularly stand out. Another important finding is that specification values ( $\mathrm{min} 900 \mathrm{~kg}$ ) have been provided for all bitumen ratios. Figure 14 show the 3D graph of the Marshall Quotient (MQ) values calculated by the simulation. The MQ value is the expression that indicates the stiffness of the samples. The ratio of the stability to flow gives the MQ value. The simulation graphs clearly shows that the CBW modification increases the stiffness of the samples (especially range of $4.0 \%-5.0 \%$ bitumen content). This study suggests that the CBW additive rate should be around $10 \%$. 


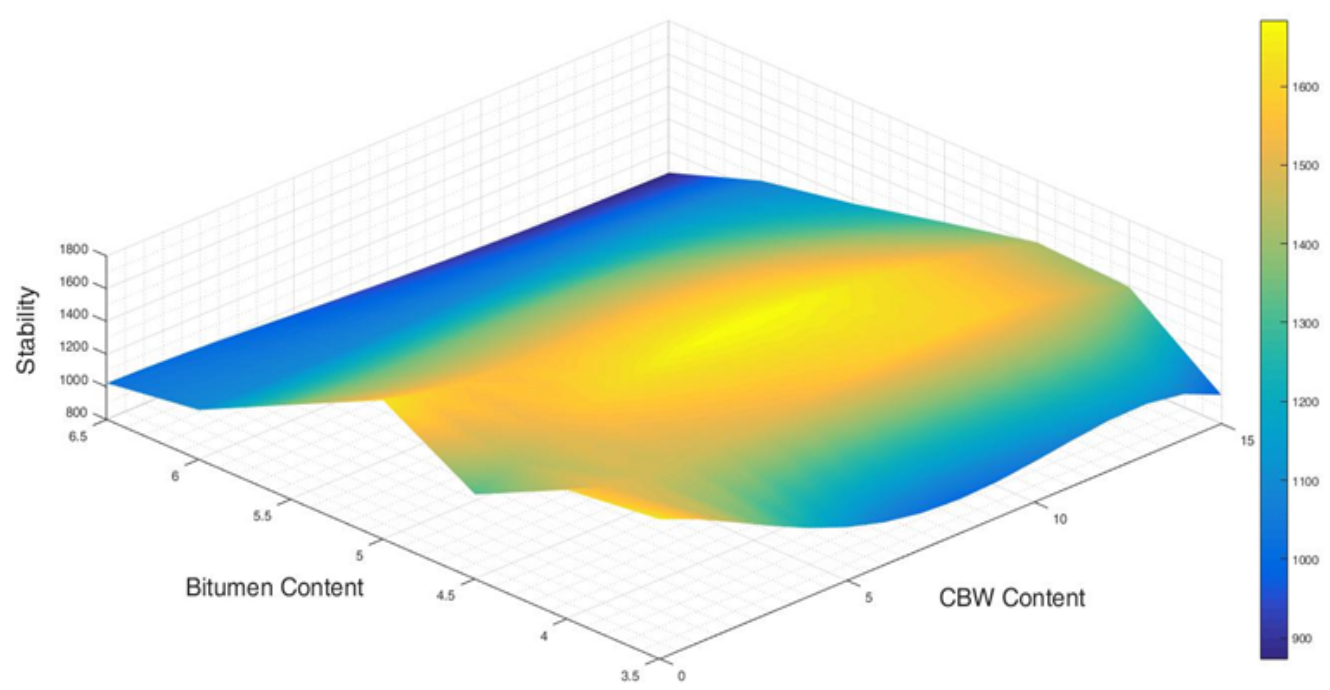

Figure 13. Simulated surface maps related to Stability depend on bitumen content and CBW content.

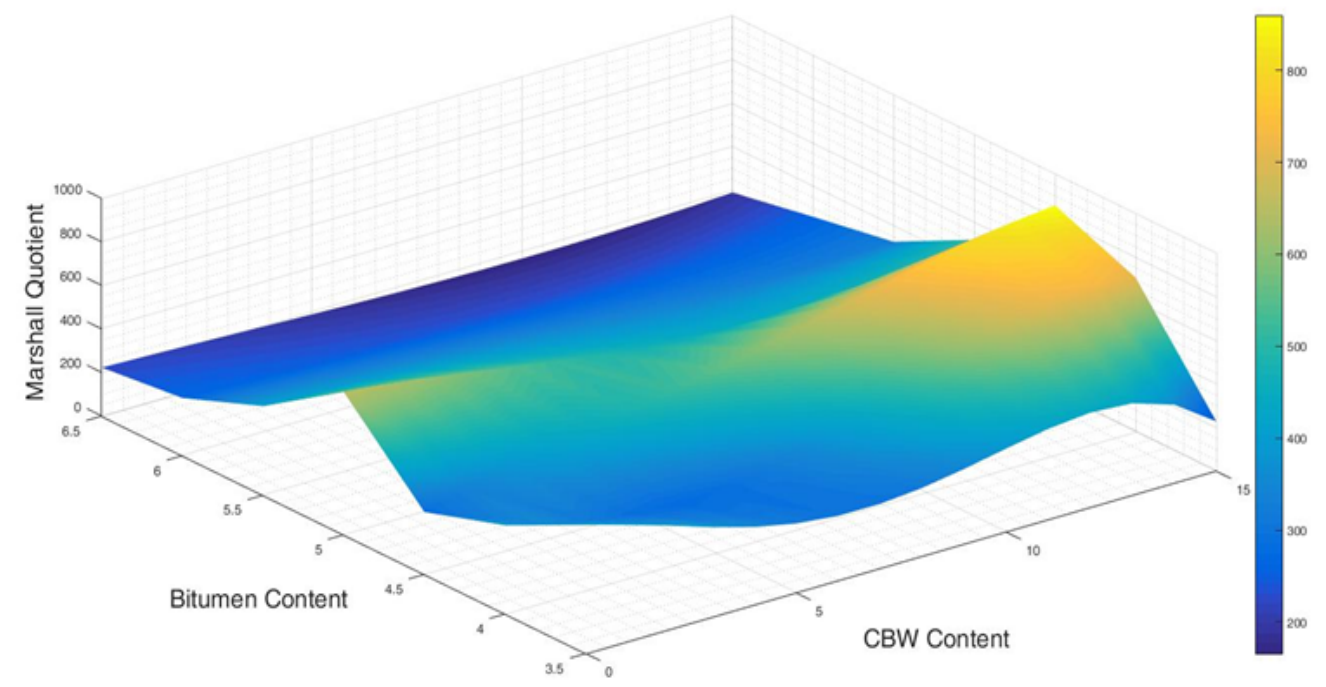

Figure 14. Simulated surface maps related to Marshall Quotient depend on bitumen content and CBW content.

\section{CONCLUSIONS}

In this research, the performance of asphalt concrete samples prepared by Marshall Test procedure was examined. Physical and mechanical properties of samples, which were modified by CBW at $5 \%, 10 \%$, and $15 \%$ by weight instead of the aggregate under $1.18 \mathrm{~mm}$ sieve, were evaluated. According to the results, it has been proved that CBW additive samples can be used in asphalt production; especially $10 \%$ additive rate showed the highest 
performance. Furthermore, a new neural network model has been developed to estimate the stability and flow values of asphalt concrete samples. The trained network has been tested with examples that have not been seen before. As a result of regression analysis, highly significant results were obtained (training and test regression analysis results of stability values; $r^{2}=0.95-0.91$; training and test regression analysis results of flow values; $r^{2}=0.91-0.87$ ). According to the simulation results with the ANN model, the high CBW content values decrease the flow value, and the stiffness of samples (Marshall Quotient values) increases. In particular, when the stability values are examined in detail, the simulation results indicate the $10 \% \mathrm{CBW}$ content.

Through this research, predicting stiffness values of asphalt concrete samples are provided. Under the same laboratory conditions, stability and flow values can be estimated by created ANN without damaging the samples, and more data can be obtained with less sample. Under the guidance of this model, time can be saved, and information about the performance of the samples can be learned much earlier. Besides, pavements produced by this technique should be preferred, in particular because of their property of preventing environmental pollution.

\section{REFERENCES}

Ahmed, T. M., Green, P. L., \& Khalid, H. A. 2017. Predicting fatigue performance of hot mix asphalt using artificial neural networks. Road Materials and Pavement Design, 18, 141-154.

Akkurt, A. 2005. Artificial Neural Networks and Turkey Electrical Consumption Forecast Model (M.Sc. Thesis), (in Turkish). ITU, Istanbul.

Alas, M., Ali, S. I. A., Abdulhadi, Y., \& Abba, S. I. 2020. Experimental Evaluation and Modeling of Polymer Nanocomposite Modified Asphalt Binder Using ANN and ANFIS. Journal of Materials in Civil Engineering, 32(10), 04020305.

Banar, M., Güney, Y., Özkan, A., Günkaya, Z., Bayrakcı, E., \& Ulutaş, D. 2017. Utilisation of waste clay from boron production as a landfill liner material. International Journal of Mining, Reclamation and Environment, 2016(200), 1-17.

Dan Foresee, F., \& Hagan, M. T. 1997. Gauss-Newton approximation to bayesian learning. In IEEE International Conference on Neural Networks - Conference Proceedings.

Ghanizadeh, A. R., \& Fakhri, M. 2018. Quasi-static analysis of flexible pavements based on predicted frequencies using Fast Fourier Transform and Artificial Neural Network. International Journal of Pavement Research and Technology, 11(1), 47-57.

Highway Technical Specifications. 2013. Ankara: General Directorate of Highways, Ankara.

Horvath, A. 2003. Life-Cycle Environmental and Economic Assessment of Using Recycled Materials for Asphalt Pavements. Berkeley, CA: University of California.

Huang, Y., Bird, R. N., \& Heidrich, O. 2007. A review of the use of recycled solid waste materials in asphalt pavements. Resources, Conservation and Recycling, 52(1), 58-73.

Jiang, J., Zhang, Z., Dong, Q., \& Ni, F. 2018. Characterization and identification of asphalt mixtures based on Convolutional Neural Network methods using X-ray scanning images. Construction and Building Materials, $174,72-80$.

Kara, C.., \& Karacasu, M. 2017. Investigation of waste ceramic tile additive in hot mix asphalt using fuzzy logic approach. Construction and Building Materials, 141, 598-607.

Karacasu, M. 2016. Road Superstructure Tests (in Turkish) (1st ed.). Eskişehir: Eskişehir Osmangazi University. 
Karasu, B., Kaya, G., \& Yurdakul, H. 2002. The Effect of Etibor Kurka Borax Company's Concentration and Derivation Wastes on the Properties of Wall Tile Bodies (in Turkish). In Proceedings of the 1st International Boron Symposium (pp. 224-228). Kutahya, Turkey.

Keskin, M., \& Karacasu, M. 2018. Performance Evaluation of Asphalt Concrete Containing Boron Wastes (in Turkish). Science and Engineering Journal of Frrat University, 30 (2), 185-192.

Keskin, M., \& Karacasu, M. 2019. Effect of boron containing additives on asphalt performance and sustainability perspective. Construction and Building Materials, 218, 434-447.

MacKay, D. J. C. 1992. Bayesian Interpolation. Neural Computation, 4(3), 415-447.

Majidifard, H., Jahangiri, B., Buttlar, W. G., \& Alavi, A. H. 2019. New machine learning-based prediction models for fracture energy of asphalt mixtures. Measurement: Journal of the International Measurement Confederation, 135, 438-451.

MATLAB Version R2015a. 2015. The Mathworks Inc. Natick, MA, USA.

Mirabdolazimi, S. M., \& Shafabakhsh, G. (2017. Rutting depth prediction of hot mix asphalts modified with forta fiber using artificial neural networks and genetic programming technique. Construction and Building Materials, 148, 666-674.

Moniri, A., Ziari, H., Amini, A., \& Hajiloo, M. 2020. Investigating the ANN model for cracking of HMA in terms of temperature, RAP and fibre content. International Journal of Pavement Engineering, 0(0), 1-13. https://doi.org/10.1080/10298436.2020.1758935

Müller, B., Reinhardt, J., \& Strickland, M. T. 1990. Neural networks an introduction. Springer-Verlag Berlin Heidelberg.

Ozgan, E. (2011). Artificial neural network based modelling of the Marshall Stability of asphalt concrete. Expert Systems with Applications, 38, 6025-6030.

Ozturk, H. I., \& Emin Kutay, M. 2014. An artificial neural network model for virtual Superpave asphalt mixture design. International Journal of Pavement Engineering, 15(2), 151-162.

Rumelhart, D. E., \& McClelland, J. L. 1986. Parallel distributed processing (Vol. 1). MIT Press, Cambridge, M.A.

Samba, M.A., Yiqiang, L., Alkhyyali, W.A., Altaher, Y.A., \& Hisayat, F. 2021. Evaluates A PVT Correlation to Estimate Dead Oil Viscosity for Libyan Crudes Using 104 Samples from Different Reservoirs. Journal of Engineering Research, Online First Article, DOI:10.36909/jer.12229

Sebaaly, H., Varma, S., \& Maina, J. W. 2018. Optimizing asphalt mix design process using artificial neural network and genetic algorithm. Construction and Building Materials, 168, 660-670.

Selman, G. Ş. 2015. Using Boron Wastes in Asphalt Pavements as Mineral Filler (M.Sc. Thesis) (in Turkish). Afyon Kocatepe University, Afyon.

Shafabakhsh, G. H., Ani, O. J., \& Talebsafa, M. 2015. Artificial neural network modeling (ANN) for predicting rutting performance of nano-modified hot-mix asphalt mixtures containing steel slag aggregates. Construction and Building Materials, 85, 136-143.

Tapkin, S. 1998. Improved Asphalt Aggregate Mix Properties by Portland Cement Modification (M. Sc. Thesis). METU, Ankara.

Tapkin, S., Çevik, A., \& Uşar, Ü. 2010. Prediction of Marshall test results for polypropylene modified dense bituminous mixtures using neural networks. Expert Systems with Applications, 37, 4660-4670.

Tapkin, S., \& Keskin, M. 2018. Number of design gyrations for $100 \mathrm{~mm}$ compacted asphalt mixtures modified with polypropylene. Journal of Engineering Research, 6 (2), 64-83. 
The Asphalt Institute. 1988. Mix design methods for asphalt concrete and other hot-mix types, Manual series No 2 .

Turan, N. G., Mesci, B., \& Ozgonenel, O. 2011a. Artificial neural network (ANN) approach for modeling Zn(II) adsorption from leachate using a new biosorbent. Chemical Engineering Journal, 173(1), 98-105.

Turan, N. G., Mesci, B., \& Ozgonenel, O. 2011b. The use of artificial neural networks (ANN) for modeling of adsorption of $\mathrm{Cu}$ (II) from industrial leachate by pumice. Chemical Engineering Journal, 171(3), 1091-1097.

Ullah, S., Tanyu, B. F., \& Zainab, B. 2020. Development of an artificial neural network (ANN)-based model to predict permanent deformation of base course containing reclaimed asphalt pavement (RAP). Road Materials and Pavement Design, 0(0), 1-19. https://doi.org/10.1080/14680629.2020.1773304

Veelenturf, L. P. J. 1995. Analysis and applications of artificial neural networks. United Kingdom: Prentice Hall Internaional (UK) Limited.

Zofka, A., \& Yut, I. 2012. Prediction of asphalt creep compliance using artificial neural networks. Archives of Civil Engineering, 58(2), 153-173. 